Laporan Penelitian

\title{
Photodynamic therapy (PDT) pada penderita karsinoma nasofaring: kajian angka harapan hidup
}

\author{
Sagung Rai Indrasari*, Bambang Hariwiyanto*, Indwiani Astuti**, \\ Soenarto Sastrowijoto* \\ *Departemen Ilmu Kesehatan Telinga Hidung Tenggorok - Bedah Kepala Leher \\ Fakultas Kedokteran Universitas Gadjah Mada/Rumah Sakit Dr. Sardjito \\ **Departemen Farmakologi Fakultas Kedokteran Universitas Gadjah Mada \\ Yogyakarta
}

\begin{abstract}
ABSTRAK
Latar belakang: Terapi karsinoma nasofaring (KNF) yang adekuat dan efektif tidak selalu tercapai di negara berkembang. Ketersediaan alat radioterapi yang tidak seimbang dengan jumlah penderita KNF menyebabkan keterlambatan jadwal terapi, sehingga berakibat pada buruknya hasil terapi. Alternatif terapi lain perlu dikembangkan untuk mengatasi permasalahan tersebut. Photodynamic therapy (PDT) telah digunakan untuk terapi tambahan pada berbagai kanker, termasuk KNF residu maupun rekuren. Tujuan: Mengetahui respon terapi lokal dan angka harapan hidup 5 tahun penderita KNF residu atau rekuren yang mendapatkan PDT. Metode: Kohort retrospektif dengan data rekam medis penderita KNF residu atau rekuren yang mendapatkan PDT di Departemen THT-KL RSUP Dr. Sardjito Yogyakarta tahun 2005-2011. Hasil: Local response rate sebesar 83,9\% dan angka harapan hidup 5 tahun penderita sebesar $60,7 \%$. Angka harapan hidup 5 tahun penderita laki-laki lebih tinggi $(73,5 \%)$ dibandingkan penderita perempuan $(42,2 \%)$, perbedaan ini bermakna secara statistik ( $\mathrm{p}=0,045)$. Angka harapan hidup 5 tahun penderita berusia $\leq 40$ tahun lebih tinggi $(76,2 \%)$ dibandingkan penderita berusia $>40$ tahun $(53,0 \%)$, meskipun tidak signifikan $(\mathrm{p}=0,417)$. Angka harapan hidup penderita yang masih terdapat tumor pada nasofaring lebih baik $(80 \%)$ dibandingkan penderita dengan hasil biopsi nasofaring negatif $(57,8 \%)$, namun tidak signifikan $(\mathrm{p}=0,638)$. Angka harapan hidup penderita berdasarkan stadium saat ditegakkan diagnosis KNF, penderita stadium awal mempunyai angka harapan hidup lebih kecil $(53,3 \%)$ dibandingkan penderita stadium lanjut $(62,1 \%)$, meskipun tidak signifikan $(\mathrm{p}=0,521)$. Kesimpulan: Local response rate PDT $83,9 \%$ dan angka harapan hidup 5 tahun sebesar $60,7 \%$. PDT merupakan modalitas terapi yang efektif untuk KNF residu maupun rekuren.
\end{abstract}

Kata kunci: Karsinoma nasofaring, photodynamic therapy, angka harapan hidup

\section{ABSTRACT}

Background: Adequate and effective nasopharyngeal carcinoma (NPC) treatment cannot be reached in developing countries. The lack of radiotherapy apparatus cause delayed treatment that bring about bad treatment results. An alternative treatment modality should be created to overcome the problem. Photodynamic therapy (PDT) has been conducted for many malignancies including recurrent or residual NPC. Purpose: To find out the local response rate and 5-year overall survival among recurrent or residual NPC patients who got PDT. Method: Retrospective cohort, data was taken from medical records of patients with PDT in ENT-H\&N Surgery Department Sardjito Hospital since 2005 until 2011. Results: Local response rate was $83.9 \%$. Five-year overall survival was $6.7 \%$. The 5-year overall survival among men was significantly higher than women $(73.5 \%: 42.2 \%) p=0.045$. The 5-year overall survival among patients $\leq 40$ years old was higher than patients $>40$ years old $(76.2 \%: 53.0 \%)$ even though it was not significant $(p=0.417)$. The 5-year overall survival among patients with tumor was higher than patients without tumor (80\%:57.8\%) although it was not significant $(p=0.638)$. The 5-year overall survival among patients with previous early stage NPC was lower than previous advanced stage 
(53.3\%:62.1\%) although it was not significant ( $p=0.521)$. Conclusion: Local response rate of PDT was $83.9 \%$ and the 5-year overall survival was $60.7 \%$. PDT was found as an effective treatment modality for recurrent or residual NPC.

Keywords: Nasopharyngeal carcinoma, photodynamic therapy, 5-year overall survival

\section{PENDAHULUAN}

Karsinoma nasofaring (KNF) merupakan keganasan terbanyak di daerah kepala leher dengan angka kematian yang tinggi. Radioterapi merupakan terapi standar KNF stadium awal. Pada KNF stadium lanjut, kombinasi radioterapi dan kemoterapi diberikan untuk mendapatkan hasil yang maksimal. Dosis radioterapi untuk tumor primer sebanyak 66-70 Gray dan 60 Gray untuk limfadenopati leher. Dosis total diberikan secara fraksinasi dengan dosis 1,8-2,0 Gray per hari, 5 hari per minggu, selama 6-7 minggu. ${ }^{1}$

Terapi KNF yang adekuat dan efektif tidak selalu bisa tercapai di negara berkembang. Ketersediaan alat radioterapi yang tidak seimbang dengan jumlah penderita KNF menyebabkan keterlambatan jadwal terapi yang berakibat pada buruknya hasil terapi di Yogyakarta. Ditemukan 50 penderita KNF pada tahun 2009-2010 di Departemen THT-KL RSUP Dr. Sardjito Yogyakarta. Sejumlah 37 penderita (74\%) harus menunggu selama lebih dari 2 bulan untuk mendapatkan radioterapi. Terlebih lagi, 10 dari penderita tersebut harus menunggu selama lebih dari 6 bulan. Penundaan terapi yang diberikan untuk penderita KNF berakibat pada hasil terapi yang sangat buruk, sehingga alternatif terapi lain perlu dikembangkan untuk mengatasi permasalahan tersebut.

Photodynamic therapy (PDT) adalah modalitas terapi non-bedah yang minimal invasif. PDT telah digunakan untuk terapi tambahan pada banyak penyakit kanker termasuk KNF. Terdapat beberapa laporan penelitian tentang penggunaan PDT untuk terapi pada kekambuhan KNF. Lofgren et $\mathrm{al}^{2}$ melaporkan pengalamannya dalam penggunaan PDT pada 4 penderita KNF rekuren. Seluruh penderita KNF rekuren tersebut mampu bertahan hidup selama 5 tahun. Hal ini menunjukkan bahwa PDT memberikan hasil terapi yang baik. Tong et $\mathrm{al}^{3}$ melakukan penelitian pendahuluan pada 12 penderita KNF yang menunjukkan respon baik terhadap terapi dan dibuktikan dengan pemeriksaan computed tommography (CT) scan atau magnetic resonance imaging (MRI) 6 bulan setelah PDT. Korbelik et $\mathrm{al}^{4}$ meneliti PDT pada tikus yang diimplan sel tumor fibrosarkoma. Penelitian ini membuktikan terjadinya acute phase response setelah dilakukan PDT.

PDT untuk terapi penderita KNF residu atau rekuren telah dilaksanakan sejak tahun 2005 di Yogyakarta. Selama kurun waktu 5 tahun (tahun 2005-2010), sebanyak 34 penderita KNF rekuren atau residu mendapatkan PDT. Penelitian ini bertujuan mengetahui respon terapi lokal dan angka harapan hidup 5 tahun (5-year overall survival) pada penderita KNF residu atau rekuren yang mendapatkan terapi PDT.

\section{METODE}

Penelitian dilakukan dengan desain cohort retrospektif, dan data diambil dari rekam medis penderita KNF residu atau rekuren yang telah mendapatkan pengobatan PDT di Departemen THT-KL RSUP Dr. Sardjito Yogyakarta antara tahun 2005-2011. Sejumlah 31 penderita KNF residu atau rekuren yang memenuhi kriteria inklusi dan eksklusi dimasukkan sebagai sampel penelitian untuk dilakukan analisis parameter klinis. Jenis histopatologi KNF adalah WHO tipe 2 atau WHO tipe 3. Tanggal diagnosis KNF adalah tanggal hasil pemeriksaan patologi anatomi (PA) pada spesimen biopsi nasofaring.

Penderita KNF residu adalah penderita karsinoma nasofaring yang telah menjalani 
pengobatan standar (radiasi atau kemoradiasi) sesuai stadium saat diagnosis ditegakkan, tetapi pada saat penilaian respon terapi masih didapatkan tumor lokal pada rongga nasofaring. Diagnosis KNF residu ditegakkan berdasarkan pemeriksaan klinis lengkap THT-KL termasuk endoskopi nasofaring, CT scan nasofaring, dan biopsi nasofaring, yang dipandu dengan endoskopi. Metastasis jauh disingkirkan dengan pemeriksaan foto Rontgen paru dan USG perut.

Penderita KNF rekuren adalah penderita KNF yang telah menjalani pengobatan standar (radiasi atau kemoradiasi) sesuai stadium saat diagnosis ditegakkan dan pada saat penilaian respon terapi dinyatakan respon komplit, tetapi pada periode follow-up kemudian didapatkan tumor lokal pada rongga nasofaring. Rekurensi ditegakkkan berdasarkan pemeriksaan klinis lengkap THT-KL termasuk endoskopi nasofaring, CT scan nasofaring dan biopsi nasofaring yang dipandu dengan endoskopi. Metastasis jauh disingkirkan dengan pemeriksaan foto Rontgen paru dan USG perut. Faktor predisposisi terjadinya KNF residu atau rekuren adalah pengobatan KNF yang tidak optimal, baik karena faktor pasien maupun faktor pemberi pelayanan. Keterbatasan ekonomi dan keterbatasan pengetahuan pasien menyebabkan pengobatan KNF tidak berjalan sesuai jadwal yang telah ditentukan. Selain itu, keterbatasan alat radioterapi menyebabkan penggunaan alat yang melebihi batas kemampuan alat, sehingga berisiko untuk terjadi kerusakan. Hal ini menyebabkan terganggunya jadwal pengobatan pasien KNF.

Data klinis dicatat dan dilaporkan sebagai data karakteristik penderita. Stadium pada saat pertama kali diagnosis KNF dicatat sebagai stadium awal (stadium I dan stadium II) dan stadium lanjut (stadium III dan stadium IV). Sebelum PDT, pasien diberi Foscan dengan dosis $0,15 \mathrm{mg} / \mathrm{kg}$ berat badan, disuntikkan melalui intravena pada vena besar di fossa kubiti. Jarak antara injeksi dengan penyinaran atau drug-light interval (DLI) adalah 96 jam. Selama menunggu penyinaran, penderita dirawat dalam ruangan dengan intensitas sinar rendah, cukup dengan lampu sebesar 90 Watt. Setelah 96 jam, penderita dibawa ke ruang tindakan di bagian THT-KL untuk mendapatkan penyinaran laser. Sinar diberikan berupa sinar laser tidak panas (non-thermal), dengan dosis 20 Joule disampaikan ke rongga nasofaring menggunakan aplikator nasofaring khusus untuk PDT. Sinar laser dimasukkan ke rongga nasofaring menggunakan fiber optic dengan fluence rate of $100 \mathrm{~mW} / \mathrm{cm}$ panjang diffuser. Penyinaran dilakukan selama 200 detik pada nasofaring kanan dan 200 detik pada nasofaring kiri. Setelah selesai penyinaran, aplikator nasofaring dilepas, penderita kembali ke ruang perawatan.

Respon terapi lokal dinilai dengan pemeriksaan klinis, pemeriksaan endoskopi nasofaring, dan CT scan kepala.

\section{HASIL}

Dari 31 sampel pada penelitian ini, sebanyak $58,1 \%$ penderita adalah laki-laki dan $41,9 \%$ penderita adalah perempuan. Sebagian besar penderita berusia di atas 40 tahun. Sebanyak 21 penderita $(67,7 \%)$ sebelumnya

Tabel 1. Karakteristik subyek penelitian $(n=31)$

\begin{tabular}{lrr}
\hline Variabel & Jumlah & \% \\
\hline Jenis kelamin & 18 & $58,1 \%$ \\
Laki-laki & 13 & $41,9 \%$ \\
Perempuan & & \\
Umur & 9 & $29,0 \%$ \\
$<40$ th & 22 & $71,0 \%$ \\
$\geq 40$ th & & \\
Stadium saat diagnosis & & \\
awal & 10 & $32,3 \%$ \\
Stadium awal & 21 & $67,7 \%$ \\
Stadium lanjut & & \\
Jenis pengobatan sebelum PDT & & \\
Radioterapi & 10 & $32,3 \%$ \\
Kemoradiasi & 21 & $67,7 \%$ \\
Hasil PA post-PDT & & \\
Tumor (+) & & \\
Tumor (-) & 5 & $16,1 \%$ \\
\hline
\end{tabular}


terdiagnosis sebagai karsinoma nasofaring stadium lanjut sehingga pengobatan yang diberikan adalah kemoradiasi.

Hasil pemeriksaan biopsi nasofaring sesudah dilakukan PDT menunjukkan sebanyak 26 dari $31(83,9 \%)$ penderita tidak terdapat keganasan di nasofaring (tumor negatif), dan sebanyak $5(16,1 \%)$ penderita masih terdapat keganasan di nasofaring (tumor positif). Jadi didapatkan local response rate sebesar 83,9\%.

Angka harapan hidup 5 tahun penderita KNF residu atau rekuren yang mendapatkan terapi PDT sebesar 60,7\%. Angka ini lebih baik dibandingkan dengan angka harapan hidup penderita KNF yang mendapatkan terapi standar radiasi maupun kemoradiasi.

Berdasarkan jenis kelamin, angka harapan hidup 5 tahun penderita laki-laki lebih tinggi $(73,5 \%)$ dibandingkan penderita perempuan $(42,2 \%)$ dimana perbedaan ini bermakna secara statistik $(\mathrm{p}=0,045)$. Mean overall survival pada laki-laki sebesar $72 \%$ sedangkan pada perempuan sebesar $45,26 \%$.

Angka harapan hidup 5 tahun berdasarkan usia pada saat penderita mendapatkan terapi PDT menunjukkan penderita berusia $\leq 40$ tahun mempunyai angka harapan hidup lebih tinggi $(76,2 \%)$ dibandingkan penderita berusia lebih dari 40 tahun $(53,0 \%)$, meskipun tidak berbeda bermakna secara statistik $(\mathrm{p}=0,417)$. Penderita KNF dengan usia lebih muda ( $\leq 40$ tahun) pada umumnya mempunyai status kesehatan yang lebih baik, sehingga angka harapan hidup 5 tahun lebih tinggi dibandingkan kelompok penderita usia $>40$ tahun. Mean overall survival pada penderita usia $\leq 40$ tahun sebesar 68,381, sedangkan pada penderita usia $>40$ tahun sebesar 57,591.

Pada analisis angka harapan hidup berdasarkan hasil biopsi nasofaring pasca PDT, didapatkan penderita yang masih terdapat tumor pada nasofaring mempunyai angka harapan hidup lebih baik (80\%) dibandingkan dengan penderita yang pada hasil biopsi nasofaring negatif $(57,8 \%)$. Hasil ini tidak bermakna secara statistik $(p=0,638)$.

Analisis angka harapan hidup penderita KNF pasca PDT berdasarkan stadium saat ditegakkan diagnosis KNF, didapatkan penderita dengan stadium awal mempunyai angka harapan hidup lebih kecil (53,3\%) dibandingkan dengan penderita stadium lanjut $(62,1 \%)$ meskipun secara statistik tidak bermakna $(p=0,521)$.

Survival Function

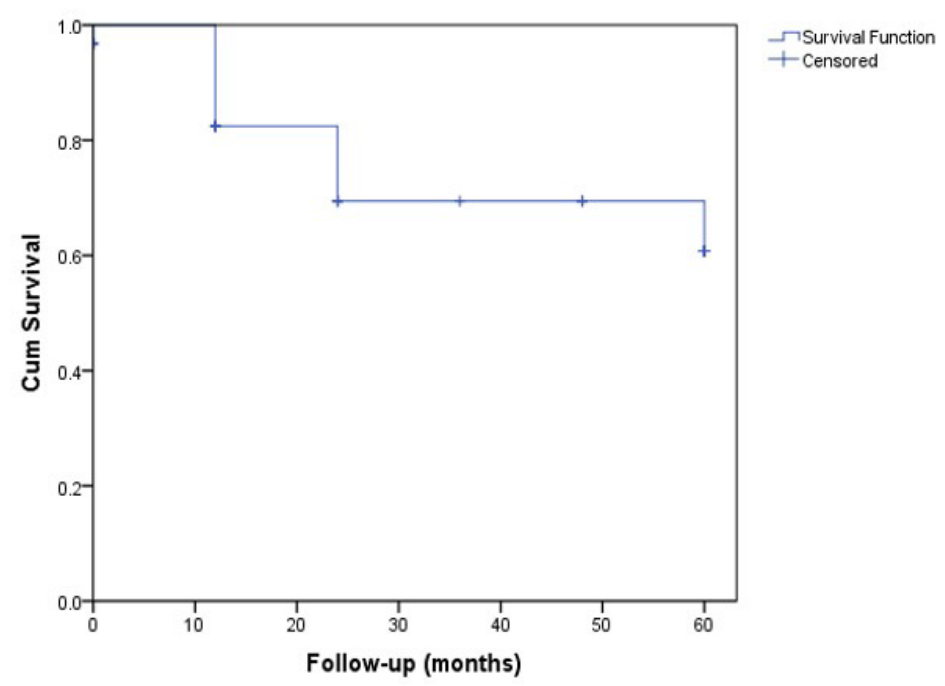

Gambar 1. Grafik Kaplan Meier angka harapan hidup 5 tahun penderita KNF pasca PDT 


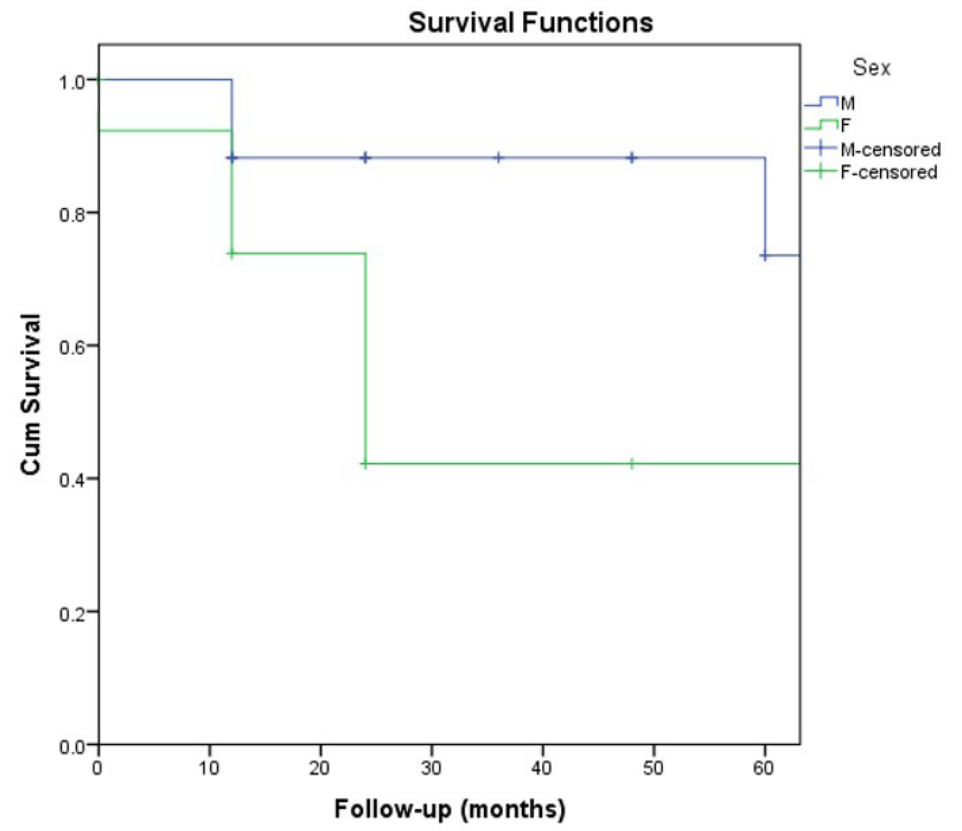

Gambar 2. Grafik Kaplan Meier angka harapan hidup 5 tahun penderita KNF pasca PDT menurut jenis kelamin

\section{DISKUSI}

Pada penelitian ini didapati local response rate sebesar $83,9 \%$, yang membuktikan bahwa Photodynamic therapy merupakan terapi yang efektif untuk mengontrol tumor lokal penderita KNF residu maupun rekuren.Wildeman et $\mathrm{al}^{5}$ melaporkan, pada penderita karsinoma nasofaring yang mendapatkan terapi standar, median overall survival pada penderita KNF sebesar 21 bulan, sedangkan median disease free survival sebesar 20 bulan terhitung sejak tanggal diagnosis ditegakkan.

Terapi pada penderita KNF residu ataupun rekuren terkadang sangat sulit. Reradiasi biasanya tidak mungkin diberikan lagi karena risiko tinggi terjadinya komplikasi radioterapi, yaitu radiotoksisitas pada struktur penting daerah kepala. ${ }^{6}$ Berbagai macam komplikasi pemberian re-radiasi dilaporkan terjadi sebesar $6-85 \% .{ }^{7,8}$ Komplikasi yang paling sering terjadi adalah xerostomia, trismus, efusi telinga tengah, sensori neural hearing loss (SNHL), osteoradionekrosis basis kranii, tulang wajah dan tulang belakang, serta yang paling berat adalah nekrosis otak yang kejadiannya dilaporkan mencapai
$20 \%{ }^{7,8}$ Neuropati radiasi bisa terjadi dan menyebabkan kesulitan menelan (disfagia). Lee et $\mathrm{al}^{7}$ melaporkan local control rate 5 tahun pada penderita KNF residu rT1 adalah sebesar 35\% dan overall survival 5 tahun pada kelompok yang sama adalah sebesar $27 \%$. Penelitian Wang ${ }^{8}$ menunjukkan angka harapan hidup 5 tahun penderita KNF residu rT1-T2 sebesar 38\%.

Kemoterapi paliatif hanya dapat diberikan pada pasien dengan kondisi kesehatan tertentu untuk memastikan tubuh bisa mentoleransi efek samping kemoterapi yang terjadi. Objective response rate pada terapi paliatif dilaporkan sebesar $10-30 \% .^{9}$ Yang et $\mathrm{a}^{10}$ melaporkan pemberian kemoterapi kombinasi platinum dan 5-FU pada KNF residu setelah pemberian terapi standar (kemoradiasi) tidak berhasil meningkatkan angka harapan hidup 3 tahun. Overall survival 3 tahun pada penderita KNF residu sebesar $71,6 \%$, sedangkan pemberian kemoterapi memberikan hasil overall survival 3 tahun sebesar $73,7 \%(p=0,440)$.

Pada penelitian ini, penderita laki-laki mempunyai angka harapan hidup 5 tahun lebih besar dibandingkan penderita perempuan. 


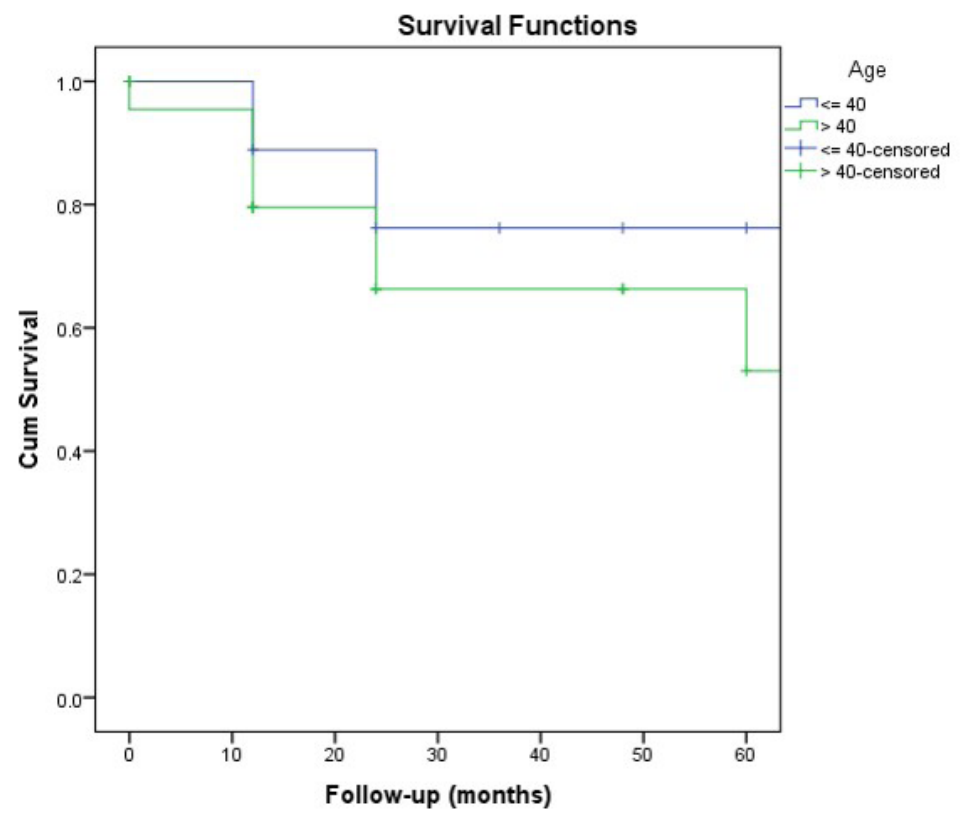

Gambar 3. Grafik Kaplan Meier angka harapan hidup 5 tahun penderita KNF pasca PDT berdasarkan usia

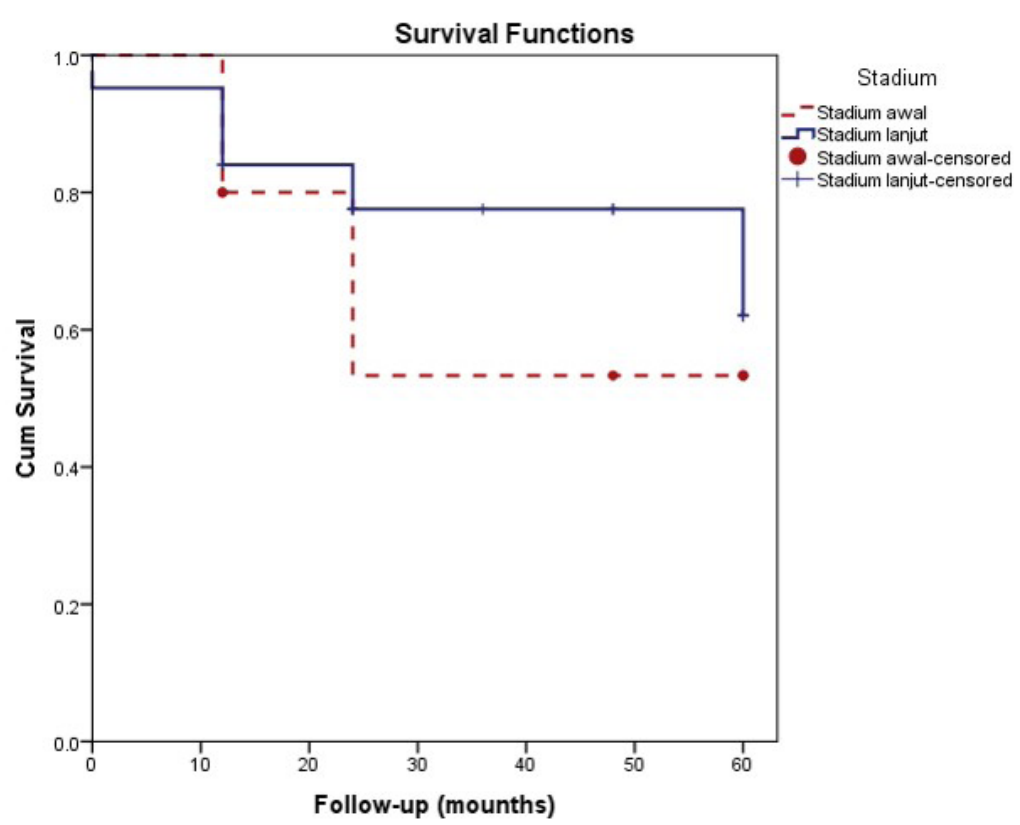

Gambar 4. Grafik Kaplan Meier angka harapan hidup 5 tahun penderita KNF pasca PDT berdasarkan stadium

Belum ada hasil penelitian atau data yang menerangkan mengapa penderita lakilaki dengan KNF residu atau rekuren yang mendapat PDT mempunyai angka harapan hidup lebih besar dibandingkan perempuan. Banyak faktor yang memengaruhi angka harapan hidup penderita KNF residu atau rekuren yang mendapatkan terapi.
Berdasarkan gambar 1 grafik Kaplan Meier angka harapan hidup 5 tahun penderita KNF pasca PDT, penderita KNF dengan usia lebih muda ( $<40$ tahun) pada umumnya mempunyai status kesehatan yang lebih baik, sehingga angka harapan hidup 5 tahun lebih tinggi dibandingkan kelompok penderita usia $>40$ tahun. Meskipun secara statistik 
tidak bermakna, dapat disimpulkan bahwa penderita KNF residu atau rekuren yang mendapatkan PDT yang berusia $<40$ tahun mempunyai angka harapan hidup lebih tinggi dibandingkan penderita usia $>40$ tahun.

Berdasarkan gambar 3, grafik Kaplan Meier Angka harapan hidup 5 tahun penderita KNF pasca PDT berdasarkan usia. Hasil ini dimungkinkan karena jumlah penderita dengan tumor positif hanya sebanyak 5 dibandingkan dengan penderita dengan tumor negatif sebanyak 26. Hasil biopsi nasofaring yang menunjukkan tumor negatif tidak menyingkirkan adanya occult metastasis yang bisa memengaruhi angka harapan hidup penderita.

Berdasarkan gambar 4 grafik Kaplan Meier, angka harapan hidup 5 tahun penderita KNF pasca PDT berdasarkan stadium sulit disimpulkan karena stadium yang dimaksudkan di sini adalah stadium penderita saat pertama kali ditegakkan diagnosis KNF. Sedangkan pada penelitian ini, pasien sudah mendapat terapi standar (radiasi atau kombinasi kemoradiasi sesuai dengan stadium penyakitnya), sehingga pasien adalah pada kondisi yang sama yaitu KNF residu atau rekuren pada tumor primer (rT1N0M0).

Banyak faktor yang mungkin memengaruhi ketahanan tubuh penderita saat mendapatkan terapi standar, misalnya jenis dan dosis kemoterapi, lama terapi, pemberian obat-obatan lain, komplikasi atau efek samping radiasi maupun kemoterapi, faktor komorbid lain dan sebagainya.

Penelitian ini menunjukkan bahwa respon terapi lokal pada penderita KNF residu atau rekuren yang diberikan PDT sebesar $83,9 \%$, dengan angka harapan hidup cukup tinggi yaitu sebesar $60,7 \%$. PDT merupakan metode pengobatan lokal dengan kemampuan penetrasi ke dalam jaringan tumor $1 \mathrm{~cm}$, sehingga untuk penderita KNF yang akan dilakukan PDT perlu dilakukan seleksi pada penderita dengan ketebalan tumor yang sesuai. Apabila PDT dilakukan pada penderita dengan ketebalan tumor $>1 \mathrm{~cm}$, maka diperlukan teknik penyinaran yang berbeda, atau PDT dilakukan lebih dari 1 kali. Telah dikembangkan teknik penyinaran PDT dengan menggunakan teknik implantasi serat fiber ke dalam masa tumor.

Hasil analisis terhadap faktor-faktor prognosis keberhasilan PDT menunjukkan bahwa jenis kelamin laki-laki mempunyai angka harapan hidup lebih tinggi $(73,5 \%)$ dibanding perempuan (42,2\%). Penderita KNF residu atau rekuren yang mendapat PDT yang berumur $\leq 40$ tahun mempunyai angka harapan hidup lebih baik $(76,2 \%)$ dibandingkan penderita umur $>40$ tahun $(53,0 \%)$. Hal ini mungkin karena penderita berumur lebih muda ( $\leq 40$ tahun) mempunyai status kesehatan atau respon imun yang lebih baik dibandingkan penderita berumur $>40$ tahun. Perlu dilakukan penelitian lebih lanjut terhadap faktor prognosis penderita KNF residu atau rekuren yang mendapatkan PDT, sehingga bisa ditentukan penderita KNF residu atau rekuren yang mempunyai harapan baik terhadap pengobatan PDT di masa yang akan datang.

Hasil pengobatan PDT pada penderita KNF residu atau rekuren setelah pengobatan standar sesuai stadiumnya, yang dinilai secara lokal berdasarkan biopsi nasofaring menunjukkan hasil yang memuaskan. Respon baik (tidak ada tumor) pada nasofaring sebanyak $83,9 \%$. Five year overall survival sebesar $60,7 \%$. Faktor-faktor prognosis seperti jenis kelamin dan usia, berhubungan secara signifikan dengan 5-year overall survival.

\section{DAFTAR PUSTAKA}

1. Wei W, Sham J, Eds. Cancer of the nasopharynx. Cancer of the head and neck. Philadelphia, WB Saunders company, 1996.

2. LofgrenLA, Hallgren S, Nilsson E, Westerborn A, Nilsson C, Reizenstein J. Photodynamic therapy for recurrent nasopharyngeal cancer. Arch Otolaryngol Head Neck Surg. 1995; 121(9):997-1002. 
3. Tong MC, van Hasselt CA, Woo JK. Preliminary results of photodynamic therapy for recurrent nasopharyngeal carcinoma. Eur Arch Otorhinolaryngol. 1996; 253(3):189-192.

4. Korbelik M. PDT-associated host response and its role in the therapy outcome. Lasers Surg Med. 2006; 38:500-508.

5. Wildeman, Renske Fles, Camelia Herdini, Rai S Indrasari, Andrew D. Vincent, Maesadji Tjokronagoro, et al. Primary treatment results of nasopharyngeal carcinoma (NPC) in Yogyakarta, Indonesia. PLOS ONE. 2013. Available from: www. plosone.org.

6. Trotti A. Toxicity in head and neck cancer: a review of trends and issues. Int $\mathrm{J}$ Radiat Oncol Biol Phys. 2000; 47(1):1-12.

7. Lee AW, Law SC, Foo W, et al. Retrospective analysis of patients with nasopharyngeal carcinoma treated during 1976-1985: survival after local recurrence. Int J Radiat Oncol Biol Phys. 1993; 26:773-782.
8. Wang CC. Re-irradiation of recurrent nasopharyngeal carcinoma. Treatment techniques and results. Int J Radiat Oncol Biol Phys. 1987; 13:953-956.

9. Gibson MK, Li Y, Murphy B, Hussain $\mathrm{MH}$, DeConti RC, Ensley J, Forestiere AA. Eastern Cooperative Oncology Group. Randomized phase III evaluation of cisplatin plus fluorouracil versus cisplatin plus paclitaxel in advanced head and neck cancer (E1395): an intergroup trial of the Eastern Cooperative Oncology Group. J Clin Oncol. May 2005; 20;23(15):3562-7.

10. Yang S, Shaomin Lin, Qiang Fu, et al. The effect of adjuvant chemotherapy on survival in patients with residual nasopharyngeal carcinoma after undergoing concurrent chemoradiotherapy. PLOS ONE. 2015. Available from: DOI:10.1371/journal. pone.0120019. 